\title{
Belief in conspiracy theories, aggression, and attitudes towards political violence
}

\author{
Federico Vegetti \\ (University of Turin) \\ vegetti.fede@gmail.com
}

\section{Levente Littvay}

(Central European University)

\begin{abstract}
In the last decade, political protest events have been rising in Western democracies. At the same time, there has been a steady increase in the diffusion of conspiracy theories in political communication, a phenomenon that has captured the interest of scholars for its growing political relevance. However, while most research focuses on the reasons why citizens believe in conspiracies, studies looking at the political-behavioral implications of such beliefs, in particular their connection to political radicalism, have been more limited. In this paper we investigate the association between people's belief in conspiracies and their propensity to endorse political violence and to legitimate radical political action. We propose a model in which belief in conspiracies mediates the impact of dispositional aggression on radical attitudes, and test it empirically on an online sample of US residents collected on Amazon Mechanical Turk. Our results suggest that conspiracy theories partially channel individuals' aggression towards political targets.
\end{abstract}




\section{Introduction}

Contemporary democracies are living an age of exacerbated political conflict, both inside and outside the institutional channels. Electoral politics seems to be moving towards greater extremism and disagreement in many established systems, to the point of threatening democratic endurance (see Somer and McCoy 2018; 2019). American politics is a particularly visible case where partisan polarization has reached concerningly high levels, to the point of threatening effective policy making (Mann and Ornstein 2012; Mansbridge and Martin 2013; McCarty et al. 2006; Thomsen 2017). In Europe, a surge of votes to extreme right-wing and populist parties has been documented all across the union (Halikiopoulou 2018; Halikiopoulou and Vlandas 2019), with some extreme cases, like Poland and Hungary, where adversarial political competition has paved the way to authoritarian and illiberal governments (Tworzecki 2019; Vegetti 2019). Moreover, while electoral participation is declining in many industrialized countries, contentious politics is on the rise (Blais and Rubenson 2013; Dalton 2008; Kriesi et al. 2012). As a recent report shows, from 2009 to 2019, anti-government protest events increased on average about 12\% every year in Europe, and 17\% in North America (Brannen et al., 2020). In other words, democratic citizens are relying more and more on alternative forms of participation, often not peaceful, to make their political point.

What these two phenomena - extremization of party politics, rise of violent protests - have in common, is that they reflect two different but related aspects of political radicalization: the emergence of actors pursuing extreme political ideals, and the justification of violence as a means to reach them (Borum 2011). Certainly, political protest is not the same as terrorism, which is the ultimate focus of research on radicalization. Reasons to protest are often legitimate, and violent outbursts can be an inevitable outcome in cases when protests are repressed, or protesters' demands are systematically ignored. However, the tendency to accept or justify violent political actions is central to both research on violent protest (Jackson et al. 2013) and terrorism (Wilner and Dubouloz 2010). In fact, in most theoretical accounts of violent extremism, the support for violent acts is regarded as a common middle step in the process of individual radicalization (see King and Taylor 2011; Kruglanski et al. 2014; McCauley and Moskalenko 2008). Hence to study the factors influencing this attitude is an important step in order to understand the political changes occurring in the recent years across many democracies.

We argue here that the recent diffusion of a multitude of political conspiracies is related to this phenomenon. In particular, we propose that the narrative offered by conspiracy theories is part of a worldview that sees the official political institutions as deceptive, and points to them as the ultimate 
scapegoat for societal problems. By constructing a system of mutually-reinforcing beliefs about the (dishonest) nature and the (malevolent) aims of the forces that regulate politics and society, conspiracy theories provide a foundation for an anti-system ideology that fuels people's animosity towards the institutions, the procedures, and the actors that are central to representative democracies. Social psychologists have long been studying why some people believe in conspiracies (see Douglas et al. 2017; 2019 for recent reviews), although efforts to understand the political behavioral implications of such beliefs have started to emerge only recently. Some studies suggest that believing in conspiracy theories promotes political action (Imhof and Bruder 2014; Kim 2019), others that it suppresses it (Jolley and Douglas 2014), and others that it bolsters only non-normative forms of participation (like refusing to pay taxes, see Imhoff et al. 2020). While empirical evidence linking belief in conspiracies to a "prompt for political action" appears unequivocal, the nature of this link is still unclear. Are conspiracy theories similar to just another form of political mobilization campaign, whether negative or not? Or is there a "dark side" to conspiracy-driven mobilization (Sternisko et al. 2020)?

With this study we aim to contribute to this body of research by investigating the link between people's belief in conspiracies and their tendency to justify radical and violent political action. In particular, we focus on the role of aggression in the process of radicalization, and propose a model of how conspiracies can channel it towards political targets. We propose a model in which belief in conspiracies mediates the relationship between dispositional aggression and endorsement of political violence, and test it at the individual level on an Amazon Mechanical Turk sample of US citizens in March 2014. Next to using validated measures of aggression (Buss and Perry 1992), belief in conspiracies (Brotherton et al. 2013)

and justification of political violence (JPV, Jackson et al. 2013), we also introduce a new battery of Legitimate Radical Political Action (LRPA). Results of structural equations models show that the path from aggression to endorsement of political violence is partly mediated by belief in conspiracies.

\section{Belief in conspiracy theories}

Definitions of conspiracy theories in the literature are multiple, and vary according to the focus of specific studies. Here we take up Byford's (2011) conceptualization, and define the conspiracy theory as a narrative, or an account of some relevant events characterized by a specific rhetorical style. First, it is based on the assumption that observable facts are the product of deliberate actions of a group of people, regardless how complex their realization may appear. Such a monistic and intrinsically deterministic view assigns immense power and control to an invisible elite whose purposes are the true driving force 
behind the political events (Clarke 2002; Keeley 1999). Second, because of the almightiness and secrecy of the actors to which they attribute the cause of all things, conspiracy theories are in fact unfalsifiable. Any piece of evidence disconfirming their claims, or any lack of evidence supporting them, will be interpreted as a sign of the hidden power of the conspirators, and therefore will become integrating part of the narrative (Keeley 1999). Thus, it is in the systematic exclusion of alternative non-conspiratorial explanations, even in the face of evidence or greater plausibility, that conspiracy theories differ from other types of investigative accounts (Aaronovich 2011).

Believing in conspiracy theories implies endorsing a specific mindset, as it would be to subscribe to a certain ideological belief. As ideological thinking implies a certain amount of constraint in the positions taken on single political issues (see Converse 1964), belief in different conspiracies also appears to be remarkably consistent. As Goertzel (1994) suggests, different conspiracy narratives are often used to provide mutually-reinforcing evidence in support to one another. Moreover, one of the best empirical predictors of a person's belief in one conspiracy, is the fact that they believe in other conspiracies. Empirical studies show that this pattern applies even when people are asked about fictitious conspiracies (Swami et al. 2011) and when the stories clearly contradict each other: in a survey study conducted by Wood and colleagues (2012), respondents who believed that Princess Diana was murdered were also more likely to believe that she had faked her own death. This suggests that people do not evaluate every single conspiracy theory on its own merits, but rather tend to buy the full package (Brotherton et al. 2013). In other words, conspiracy theories collectively form a system of mutually-reinforcing narrations that confirm each other's idea about the processes regulating political events. Such a system can be regarded as a proper worldview, as it is based on a set of core assumptions regarding the functioning of political reality that are common to all conspiracy theories.

But what is the content of this worldview? In the case of left-right ideology, it has been suggested that the core factors providing logical constraint to people's political beliefs are their views with respect to economic equality and social change (Jost 2006). A recurring theme in conspiracy theories is that the decisional power and control over the mechanisms that regulate the political world are held by elites typically driven by cynical purposes, with public institutions being more or less consciously colluded with them. Wood et al. argue that this narrative should be called deceptive officialdom, that is "the idea that authorities are engaged in motivated deception" (Wood et al. 2012, p. 768). This view is reinforced 
by studies showing a significant association between conspiracy belief, political cynicism, and negative attitudes towards the authority (Swami et al. 2011).1

But what are the factors making some individuals more likely to buy into the anti-system ideology promoted by conspiracy theories? Research in this respect is vast, however some common threads can be identified. Early explanations have regarded conspiracy belief as a form of collective paranoia. According to Hofstadter (1965) one of the central aspects of conspiratorial narratives is the "feeling of persecution" that they entail. However, whereas paranoia is a clinical condition affecting individuals, conspiracy theories imply a collective dimension that separates them from individual delusions (Bale 2007; Byford 2011; Zonis and Joseph 1994). While people suffering from paranoia tend to see hostile plots perpetrated against themselves, conspiracy theory believers typically describe machinations against their own group (Bartlett and Miller 2010; Sapountzis and Condor 2013). The collective dimension of conspiracy belief has been emphasized by recent political behavioral research, which found an empirical association with factors reflecting a group-centered mindset, such as partisanship (Oliver and Wood 2014), political extremism (van Prooijen et al. 2015) and populism (Silva et al. 2017).

Another class of factors that are related with belief in conspiracies regards individuals' personality and their cognitive style. For instance, some traits that are strongly connected to conspiracy belief are people's tendency to make causal attributions of phenomena to hidden forces, and their preference for Manichean types of narrative (Oliver and Wood 2014). Consistently, studies found significant correlations between belief in conspiracies and belief in paranormal or supernatural forces (Brotherton et al. 2013; Bruder et al. 2013). Researchers have also focused on the impact of Big Five personality traits on individual differences in conspiracy belief. Empirical findings suggested a negative correlation between belief in conspiracies and agreeableness (Bruder et al. 2013; Swami et al. 2010, 2011) and a positive association with openness to experience (Swami et al. 2010), although other studies could not replicate the same results, suggesting that the relationship between personality on conspiracy belief is somewhat complex and possibly mediated by neglected factors (Brotherton et al. 2013).

Finally, and importantly, belief in conspiracies is associated with a number of variables that reflect individuals' lack of significance, that is, the "fundamental desire to matter, to be someone, to have respect" (Kruglanski et al. 2014, p. 73). Factors that have been found to play a role in this respect include feelings of powerlessness, uncertainty, anomie, and low interpersonal trust (Abalakina-Paap et al. 1999;

1 Other ideas can contribute to other beliefs. Lewandowsky et al. (2013) provide a more policy-based account, showing that rejection of climate science is related to endorsement of free markets. Oliver and Wood (2014) show that people tend believe in theories where the conspirators are said to belong to an adversary political group. 
Goertzel 1994; Grzesiak-Feldman and Irzycka 2009; Van Prooijen and Jostmann 2013). Moreover, Uscinski and Parent (2014) show that conspiracy theories flourish among "political losers", that is, people who are subdued in a power asymmetry, like Republican supporters under a Democratic president and vice versa. All these factors reflect a certain degree of existential threat, which can be real or potential, and affect single individuals or social groups. This point is relevant because such a loss of significance is believed to provide the motivational basis for personal enhancement through radical actions (see Kruglanski et al. 2013, 2014).

\section{Conspiracy theories in the process of radicalization}

Research on radicalization is mostly focused on forms of violent extremism, such as terrorism (Borum 2011; King and Taylor 2011; Kruglanski et al. 2014; McCauley and Moskalenko 2011; Moghaddam 2005; Wilner and Dubouloz 2010). In virtually all recent accounts, radicalization is conceptualized as a process, or a pathway, that starts with common citizens and ends with individuals who are willing to take many lives, sometimes including their own, to pursue a political ideal. While terrorism is the final, extreme outcome of this process, the acceptance of violence is usually seen as a middle step in the path of individual radicalization. As Kruglanski and colleagues argue, radical behavior is a means to reach a focal goal (such as e.g. making a political statement), which coexists with other alternative goals (e.g. going about everyday life). The more the focal goal is important, to the detriment of alternative goals (quite literally, as it might even overshadow the goal to survive), the greater is the degree of radicalization (Kruglanski et al. 2014). In this view, supporting or justifying political violence implies that the focal goal is important, but not that important to dominate the other goals in a person's life. Nevertheless the focal goal is there, and in the right circumstances it might become so central to determine behavior. As Jackson and colleagues' point out, "[p]eople who think it is morally acceptable to use violence to achieve certain goals may be more likely to engage in the act if the situation arose, less likely to condemn other people's behavior, and less likely to assist legal authorities in the detection and prosecution of violent acts" (Jackson et al. 2013, p. 480).

In a general model of radicalization (see King and Taylor 2011) the pathway starts with a set of individual predispositions, which stem from a person's life conditions and dispositional traits, and ends with a resulting attitude or behavior. In between the two there are one or more intervening factors, like religion or the active recruitment by extremist organizations, that play a crucial role in the chance of radicalization (see Figure 1). 


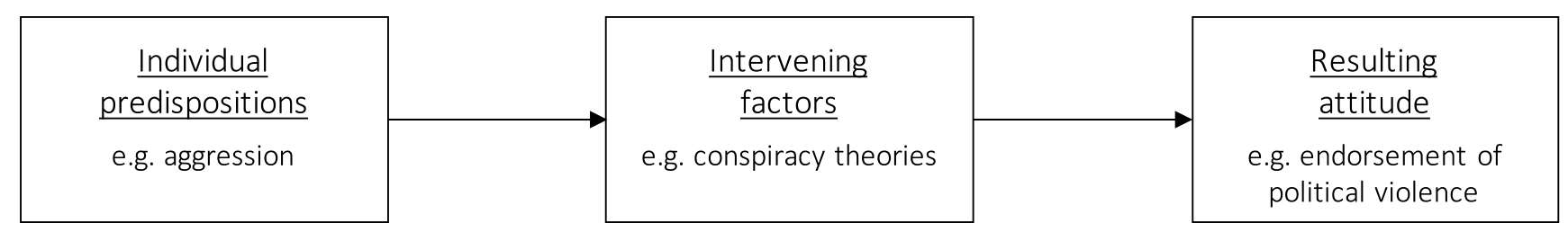

Figure 1: Pathway from predispositions to attitudes

The starting point of many theoretical models lies in a number of predispositional factors that make some individuals more likely than others to embark on a pathway towards radicalism. Interestingly, many common factors have been identified independently in the contexts of research on radicalization and conspiracy theory belief. Most of them revolve around the presence of an individual crisis, or again, loss of significance (Kruglanski et al., 2014). While research on terrorism usually focuses on relative deprivation, moral outrage and identity-related issues (King and Taylor 2011; Moghaddam 2005; Sageman 2008; Wilner and Dubouloz 2010), research on conspiracy belief emphasizes anomie, aggression, lack of self esteem, lack of control, uncertainty, hostility and feelings of powerlessness as important correlates of conspiracy belief (Abalakina-Paap et al. 1999; Bruder et al. 2013; Goertzel 1994; Swami et al. 2011; Van Prooijen and Jostmann 2013). In general, a common factor that seem to be central to both streams of research are a heightened sense of resentment for one's own conditions, which can result into plain hostility towards the relevant out-group when activated. In the case of conspiracy theories, the out-group are arguably the governing elites, which are perceived as the cause of one's own problematic conditions. In fact, as Abalakina-Paap and colleagues argue (1999), conspiracy theories often provide an outlet for hostility and aggression. As individuals endorsing conspiracy theories are likely to embrace populist attitudes (Silva et al. 2017), which have been shown to build in part upon feelings of anger (Rico et al. 2017) it is reasonable to look at aggression as a starting point for a path towards radicalization fueled by conspiracy theories.

Once a predisposition is there, the presence of intervening factors that point the individual path towards radicalism is a crucial element. In the case of research on homegrown terrorism, which is typically focused on members of Muslim minorities in Western countries, two important sources are religion and established extremist organizations. In the case of research on conspiracy belief, the emphasis is on the monistic causal explanations offered by many conspiracy theories, which helps people see reality as something understandable and predictable (Van Prooijen and Jostmann 2013). Like religions, conspiracy 
theories offer simplified and intuitive accounts for events, often presenting them as conflicts over sacred values (Franks et al. 2013). Moreover, like religious faith, conspiracy belief defines the borders of a community (Byford 2011). By granting individuals a source of social self-categorization, the membership to the group of believers, both religion and conspiracy theories can provide a sense of perceived external approval to one's feelings and attitudes, therefore and again contributing to uncertainty reduction (Hogg 2000).

Seeking to reduce uncertainty by relying on simplistic narrations or by joining a group of believers is not a sufficient condition for radicalization. Endorsement of violence is greatly prompted by the antisystem worldview that such narrations promote. Scholars seem to agree that the structure of conspiracy belief resembles ideology in that beliefs in different conspiracies reinforce one another into a general monological narrative. The constraint among a person's views in an ideological system is given by the logical coherence that a certain type of opinion towards different attitude objects requires (see Converse 1964). As a simple example, if a person thinks that wealth should be better redistributed in order to improve life's quality of the disadvantaged, s/he should also think that the state should have a greater regulatory role in administering taxes and providing social services. The connection between these two attitudes does not come from the fact that they are implied or dependent on one another (in fact, redistribution could be achieved in different ways than relying on the role of the state), but that they reflect the same underlying philosophy, i.e. that more equality is the ultimate aim of political power. Similarly, believing in two different conspiracies does not mean that they must logically imply one another - as the study by Wood et al. (2012) cleverly shows - but that the narrative that they both propose resonate with an underlying idea (in this sense, what is called "belief" in conspiracy theories should be rather called "acceptance" of conspiracy theories). Such an idea is that official power institutions are secretly colluded with one another, and act the interest not of the citizens, whom they are meant to serve and/or represent, but of some secret and powerful elites. This narrative resembles the one given by many radical Muslim groups who regard the West as a singular entity on war against Islam (Sageman 2008). More generally, both extremist narrations and conspiracy theories identify and point at precise enemies. In this way, they both fulfill the function of displacing individuals' resentment and aggression onto outgroups by making them scapegoats (Abalakina-Paap et al. 1999; Goertzel 1994; Moghaddam 2005; Young 1990). Group dynamics play a similar role. Conspiracy believers like to be "in the know", share precious non-mainstream information with other believers, and by doing so increase their own popularity in the community (Byford 2011). However, when group boundaries are established, they can lead to 
isolation of the members, attitudinal polarization, and increased despise for the out-groups (McCauley and Moskalenko 2008). Both these factors may prompt individuals to think that political adversaries are enemies, that standard forms of political competition may be not effective to defeat them, and therefore that violence is a justifiable or even necessary undertaking to bring political justice.

\section{Data, variables, and model specification}

We provide empirical support to our theoretical model using data collected by the Political Behavior Research Group at CEU (PolBeRG), with Amazon's service Mechanical Turk in March, 2014. 646 American citizens of voting age volunteered to participate in the survey that contains several experiments and a multitude of batteries of questions designed to tap into the demographic, psychological, sociological and political characteristics of individuals.2 Financial incentives were offered as rewards for decisions that the respondents made in some of the experiments, and several attention checks were included throughout the survey (see Oppenheimer et al., 2009), likely contributing to the quality of our data. As for the sample composition, $52.5 \%$ of the respondents are women, the age ranges from 18 to 77, with an average of 35.7 and a median of 32, 5.7 years lower than the national median. 3 The sample is markedly more educated than a nationally representative sample, as $92 \%$ of the respondents reported having more than 12 years of formal education. Also, the sample has a noticeable skew towards the liberal side of the ideological spectrum, with $52 \%$ of the respondents reporting to be slightly liberal to very liberal, and only $25 \%$ slightly to very conservative. Regarding race, whites are clearly oversampled, with a prevalence of $82 \%$, while $5.5 \%$ identify as African-American, $3.8 \%$ as Hispanics, and $3.6 \%$ as Asian.

The constructs we discussed were all explicitly measured. First, our predispositional factor is the respondents' level of aggression, which we measure using the well-known and validated Buss-Perry Aggression scale (Buss and Perry 1992). Second, our intervening factor is the respondents' belief in conspiracies. Following Brotherton et al. (2013), the subjects were asked to assess the veracity of fifteen conspiratorial statements on topics ranging from government and global organized malevolence to extraterrestrial cover-ups. The index is made of different facets exploring different kinds of conspiratorial thinking, however since we do not expect different facets to have different effects on our outcome variables, we keep all items together in one latent construct that we name "conspiracy belief".

2 The total sample size is 694 , however we remove all the respondents participating to the pilot survey.

3 See https://www.statista.com/statistics/241494/median-age-of-the-us-population/ 
Finally, we use two different latent constructs to measure our outcome, respondents' attitudes towards political violence. The first is the four item scale by Jacskon et al. (2013) to measure our subjects' principled justification of violence as an adequate response to perceived injustice or unfairness (JPV). The second is a battery developed by us, called "Legitimate Radical Political Action" (LRPA). It contains six items inquiring about the respondents' willingness to accept violence as a justified mean to achieve political ends. Because this is a new instrument developed for this study, we report here the wording of the items.4

1. In extreme circumstances, it is acceptable for someone in your community to physically harm a government official to express political discontent

2. In extreme circumstances, it is acceptable for someone in your community to protest violently to express political discontent

3. In extreme circumstances, it is acceptable for someone in your community to destroy property to express political discontent

4. In extreme circumstances, it is acceptable for someone in your community to publicly call for the boycott of an election to express political discontent

5. In extreme circumstances, it is acceptable for someone in your community to call for violence to express political discontent

6. In extreme circumstances, it is acceptable for people in your community to arm and isolate themselves to express political discontent

We used the same approach to measure the other psychological constructs relevant to our study. Three more constructs were pooled together in a battery of 43 items. The right-wing authoritarianism (RWA) with 19 items proposed by Altemeyer (2007). Social dominance orientation (SDO) reflects people's justification of social hierarchies and of the privileges that some groups have over others; SDO is measured with 16 likert items, following Sidanius et al. (2001). Finally, 8 items were used for tapping into the respondents' sense of internal self-efficacy (Chen et al., 2001), or their perception of their personal ability to carry out tasks and bring about desirable outcomes. We also include several demographic and political controls in our models: gender (a dummy variable taking value 1 for female

4 The response categories range from 1 ("Completely Agree") to 7 ("Completely Disagree"). See the Appendix 1 for the wording of the other relevant indicators. 
respondents), education (7 ordered categories, ranging from no high school diploma to $\mathrm{PhD}$ ), age (in decated), race (a dummy indicating whether the respondent is not white), and ideology (the common 7point scale ranging from extremely liberal to extremely conservative).

Some of the scales we use in this study had to be abbreviated to keep the length of the survey within tolerable limits and avoid respondent fatigue. This was done by assigning to each respondent only a subset of all the items considered for the measurement of any given trait. However, as the selection of items assigned to each respondent was random, the system missing data can be considered completely random. This allows an efficient handling of the missing observations via a full information maximum likelihood technique (see Enders 2010). The effect of the omissions, if any, would be to decrease the reliability of our scales, thus elevating type II errors and attenuating some of our coefficients.5

Due to the complexity and sheer number of relationships that need to be estimated, we use structural equation models (SEM), including belief in conspiracies as a mediator (Baron and Kenny, 1986) of the effect of aggression on the political violence and LRPA batteries. We fit two models, one for each of the two outcome batteries. Aggression is always specified as independent, in line with the extant psychometric literature suggesting that this is a dispositional trait (see Buss and Perry, 1992), unlikely to vary as a consequence of one of our predictors and controls. The other independent variables are the same in all models. Psychological constructs are modeled as latent, whereas demographic variables are manifest. We set free covariance between all latent predictors and all manifest predictors.

\section{Results}

The results are shown in figures 2 and 3.6 The figures show a schematic representation of our SEM models with standardized coefficients associated with the arrows connecting the variables. For both models, the root mean square error of approximation (RMSEA) is 0.051, and the standardized root mean square of the residual (SRMR) is 0.095, implying that the model fits are acceptable. The two models show a remarkable similarity in terms of which predictors are significantly associated with the two outcome variables, as well as with the coefficients associated with the predictors. This suggests that the two variables we use to measure individuals' attitudes towards political violence have very similar properties.

5 The batteries for which we used these strategies are the LRPA scale (where we showed to each respondent 4 items out of 6 ), the aggression scale (14 items out of 29), the RWA scale (11 items out of 19), the SDO scale (9 items out of 16), and the internal self-efficacy scale (5 items out of 8 ).

6 See Appendix 2 for the full results. 


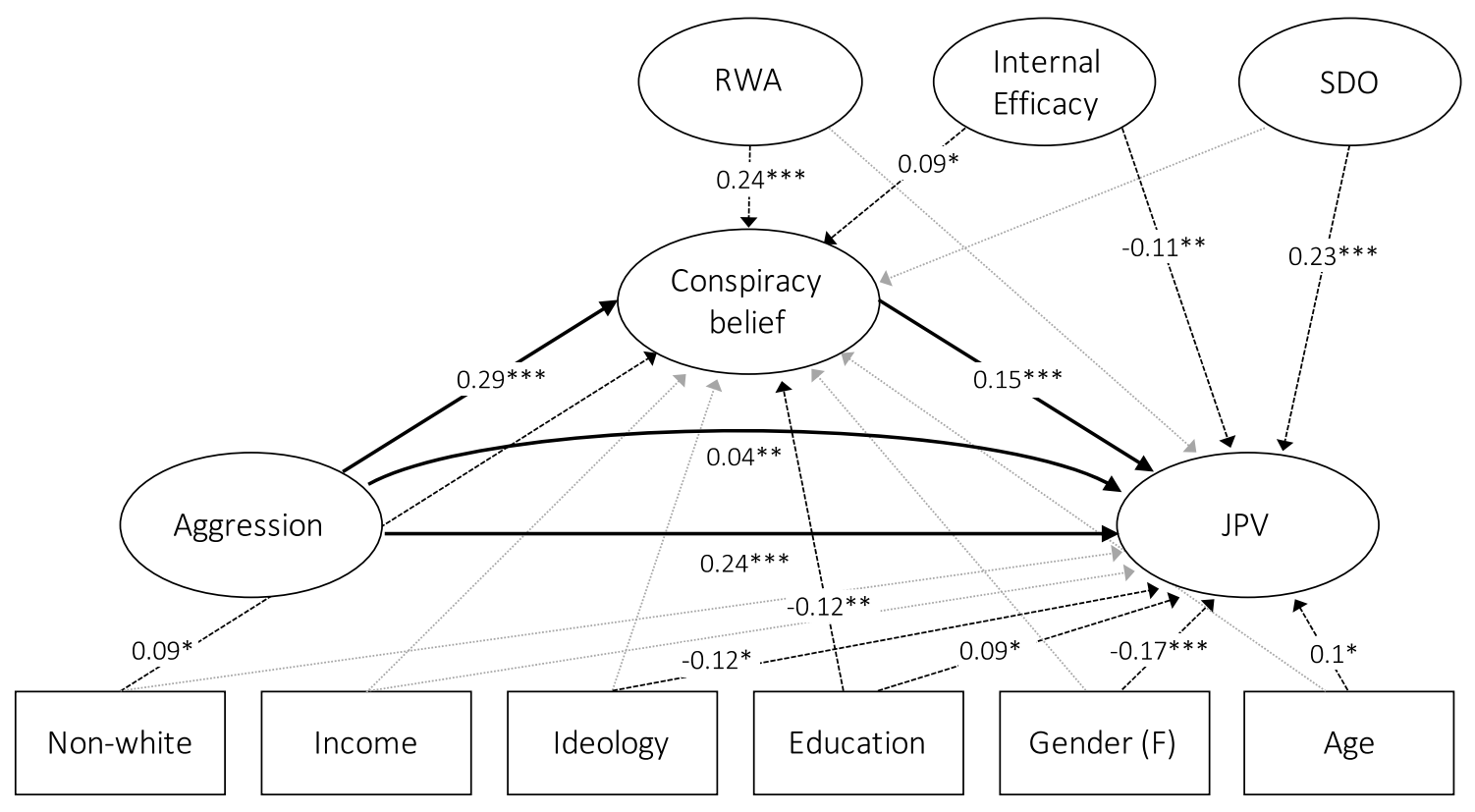

Figure 2: SEM model of justification of political violence (JPV). All coefficients are standardized. Black straight arrows are components of the mediation, curved arrow is the indirect effect (see Silva et al., 2019), dashed arrows are other significant effects ( $p<0.05)$, and grey arrows are insignificant effects. Indicators of latents and covariances between latents and exogenous variables are omitted. $* * *=p<$ $0.001 ; * *=p<0.01 ; *=p<0.05$

In both cases, right wing authoritarianism is positively correlated with belief in conspiracies, but not with the endorsement of radical action. Authoritarian respondents are more likely to believe in conspiracies, but they are no more likely to endorse violence to make their political points. The opposite pattern emerges for people who score high on the social dominance orientation scale, who appear significantly more likely to endorse political violence and legitimize radical action, but they are not more likely than their peers to believe in conspiracies. Respondents with lower levels of internal self-efficacy are also significantly more likely to believe in conspiracies, but they score lower in their attitudes towards political violence. The first finding is somewhat surprising, given the literature showing that uncertainty and lack of control are associated with higher chances to believe in conspiracies (see Van Prooijen and Jostmann 2013). Looking at the manifest predictors, females are less likely to endorse political violence and radical action, but no different from men in their propensity to believe in conspiracies. More educated people are less likely to believe in conspiracies, and they also appear more 
likely to endorse political violence and legitimize radical political action. People belonging to a racial minority score higher on the conspiracy belief scale, while they are no different from white Americans in their propensity to endorse political violence or radical action. Finally, ideology has a negative effect on the endorsement of political violence, meaning that liberal respondents are more likely to hold this attitude, although there is no effect on the LRPA index.

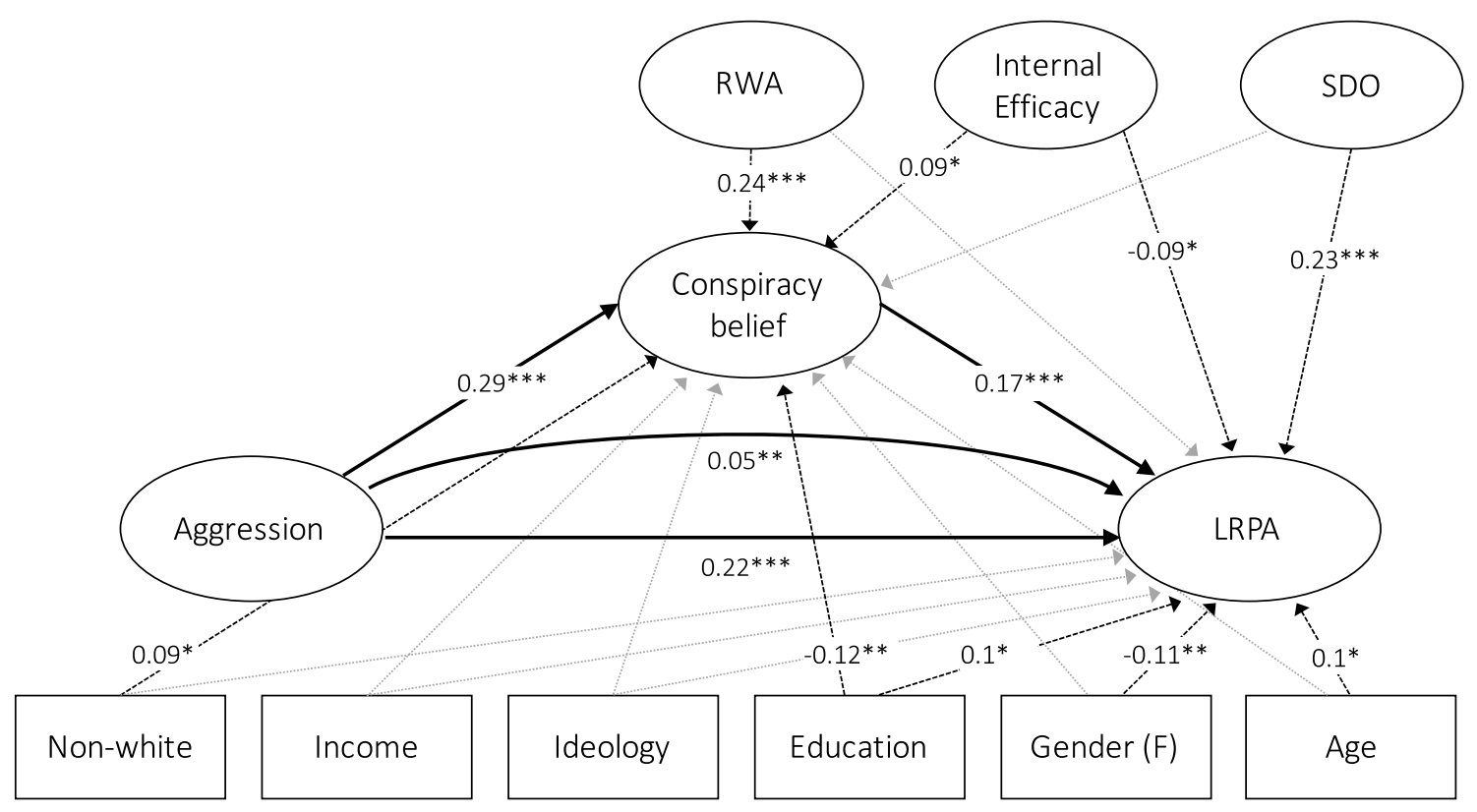

Figure 3: SEM model of legitimization of radical political action (LRPA). All coefficients are standardized. Black straight arrows are components of the mediation, curved arrow is the indirect effect (see Silva et al., 2019), dashed arrows are other significant effects ( $p<0.05$ ), and grey arrows are insignificant effects. Indicators of latents and covariances between latents and exogenous variables are omitted. $* * *=p<0.001 ; * *=p<0.01 ; *=p<0.05$

Moving to the three variables of interest, the results go in the expected direction. Belief in conspiracies is significantly associated with endorsement of political violence $(r=0.15)$, as well as legitimization of radical action $(r=0.17)$. Aggression is a significant predictor of endorsement of political violence $(r=$ 0.24 ), the LRPA scale ( $r=0.22)$, and belief in conspiracies ( $r=0.29$ in both models). Importantly, we find that belief in conspiracies mediates the effect of aggression on both political violence and the legitimation of political violence. In both figures, the curved arrow going from aggression to the two outcome variables shows the size and significance of the mediated effect $(r=0.04$ for the JPV model 
and $r=0.05$ for the LRPA model). The size of the mediated effect accounts for about $16 \%$ of the total effect of aggression on JPV (which is obtained adding the mediated effect to the direct effect), and about $18 \%$ of the total effect on the LRPA index. This is only a share of the total effect, however it would be naive to expect that the only mechanism by which aggression affects political radicalism is through conspiracy theories. Hence, in sum, this finding confirms our expectation: conspiracy theories serve to a certain extent as a way to channel citizens' hostility towards the realm of politics.

\section{Concluding remarks}

In the last decade, political protest events have been rising in Western democracies. At the same time, there has been a steady increase in the diffusion of conspiracy theories in political communication, a phenomenon that has captured the interest of scholars for its growing political relevance. In this paper we investigate the nature of the association between the two phenomena, looking at citizens' attitudes towards political violence. Drawing from psychological literature conceptualizing the process of radicalization as a pathway from individual predispositions to radicalism, we theorize that conspiracy theories act as intervening factor channeling people's aggression towards political goals. We provide empirical support to our expectations using data from an MTurk sample of American residents interviewed in 2014. Our outcome is measured using a battery of justification of political violence (Jacskon et al. 2013) as well as a brand new scale of legitimization of radical political action developed by us.

Our findings agree with most of our theoretical expectations. Belief in conspiracies emerges from our two models as a chiefly anti-system mindset, fueled by higher propensities for aggressiveness, as well as by various forms of social exclusion, and with the potential to effect violent attitudes and behaviors. The respondents who are most likely to adhere to a conspiracy-endorsing mindset appear to be those belonging to less privileged societal groups, such as racial minorities and less educated segments of the population. They are more likely to have an authoritarian orientation, but, unlike the typical endorsers of violence, they do not appear to have exacerbated social dominance orientations. This suggests that conspiracy believers, while having authoritarian, uncompromising views on social matters, are not particularly adamant to legitimize the morality of existing systemic inequities. Conspiracy believers strive for social order and moral absolutes, but not for the ones that the current political mainstream has on offer. 
Despite these notable differences between the typical believers in conspiracies and the typical supporters of violence, they all have in common a higher propensity for aggressiveness, as belief in conspiracy is a significant predictor of justification of political violence and legitimization of radicalism. We argued that belief in conspiracies may constitute an intervening factor in the pathway from aggressiveness to political violence. Our results show that conspiracy belief indeed mediates, albeit to a small extent, the impact of aggression on our outcome variables. While this is certainly not the only pathway leading aggressive individuals to political radicalism, our mediation analysis lends credence to the idea that, at least in the case of some individuals, belief in conspiracies can channel aggressiveness towards violent behavior and attitudes. 


\section{References}

Aaronovitch, D. (2009). Voodoo Histories: The Role of the Conspiracy Theory in Shaping Modern History. London: Jonathan Cape.

Abalakina-Paap, M., Stephan, W. G., Craig, T., \& Gregory, W. L. (1999). Beliefs in Conspiracies. Political Psychology, 20(3), 637-647.

Bale, J. M. (2007). Political paranoia v. political realism: on distinguishing between bogus conspiracy theories and genuine conspiratorial politics. Patterns of Prejudice, 41(1), 45-60.

Bartlett, J., \& Miller, C. (2010). The power of unreason. Conspiracy theories, extremism and counterterrorism (Demos).

Blais, A., \& Rubenson, D. (2013). The Source of Turnout Decline: New Values or New Contexts? Comparative Political Studies, 46(1), 95-117.

Borum, R. (2011). Radicalization into Violent Extremism I: A Review of Social Science Theories. Journal of Strategic Security, 4(4), 7-36.

Brannen, S. J., Stirling Haig, C., \& Schmidt, K. (2020). The Age of Mass Protests: Understanding an Escalating Global Trend. Center of Strategic and International Studies (CSIS).

Brotherton, R., French, C. C., \& Pickering, A. D. (2013). Measuring belief in conspiracy theories: the generic conspiracist beliefs scale. Frontiers in Psychology, 4(279).

Bruder, M., Heffke, P., Neave, N., Nouripanah, N., \& Imhoff, R. (2013). Measuring individual differences in generic beliefs in conspiracy theories across cultures: Conspiracy Mentality Questionnaire. Frontiers in Psychology, 4(225).

Byford, J. (2011). Conspiracy Theories: A Critical Introduction. Bakingstoke: Palgrave Macmillan.

Clarke, S. (2002). Conspiracy Theories and Conspiracy Theorizing. Philosophy of the Social Sciences, $32(2), 131-150$.

Converse, P. E. (1964). The Nature of Belief Systems in Mass Publics. In D. E. Apter (Ed.), Ideology and Discontent (pp. 206-261). London: Free Press of Glencoe.

Dalton, R. J. (2008). Citizen Politics: Public Opinion and Political Parties in Advanced Industrial Democracies. Washington: CQ Press.

Douglas, K. M., Sutton, R. M., \& Cichocka, A. (2017). The psychology of conspiracy theories. Current Directions in Psychological Science, 26(6), 538-542.

Douglas, K. M., Uscinski, J. E., Sutton, R. M., Cichocka, A., Nefes, T., Ang, C. S., \& Deravi, F. (2019). Understanding Conspiracy Theories. Political Psychology, 40(S1), 3-35. 
Enders, C. K. (2010). Applied Missing Data Analysis. The Guilford Press.

Franks, B., Bangerter, A., \& Bauer, M. W. (2013). Conspiracy theories as quasi-religious mentality: an integrated account from cognitive science, social representations theory, and frame theory. Frontiers in Psychology, 4(424). doi:10.3389/fpsyg.2013.00424

Goertzel, T. (1994). Belief in Conspiracy Theories. Political Psychology, 15(4), 731-742.

Grzesiak-Feldman, M., \& Irzycka, M. (2009). Right-wing authoritarianism and conspiracy thinking in a Polish sample. Psychological Reports, 105(2), 389-393.

Halikiopoulou, D. (2018). A Right-wing Populist Momentum? A Review of 2017 Elections Across Europe. JCMS: Journal of Common Market Studies, 56(S1), 63-73.

Halikiopoulou, D., \& Vlandas, T. (2019). What is new and what is nationalist about Europe's new nationalism? Explaining the rise of the far right in Europe. Nations and Nationalism, 25(2), 409-434.

Hofstadter, R. (1965). The paranoid style in American politics and other essays. New York: Knopf.

Hogg, M. A. (2000). Subjective Uncertainty Reduction through Self-categorization: A Motivational Theory of Social Identity Processes. European Review of Social Psychology, 11(1), 223-255.

Imhoff, R., \& Bruder, M. (2014). Speaking (Un-)Truth to Power: Conspiracy Mentality as a Generalised Political Attitude. European Journal of Personality, 28(1), 25-43.

Imhoff, R., Dieterle, L., \& Lamberty, P. (2020). Resolving the puzzle of conspiracy worldview and political activism: Belief in secret plots decreases normative but increases non-normative political engagement. Social Psychological and Personality Science, in press.

Jackson, J., Huq, A. Z., Bradford, B., \& Tyler, T. R. (2013). Monopolizing force? Police legitimacy and public attitudes toward the acceptability of violence. Psychology, Public Policy, and Law, 19(4), 479497.

Jolley, D., \& Douglas, K. M. (2014). The social consequences of conspiracism: Exposure to conspiracy theories decreases intentions to engage in politics and to reduce one's carbon footprint. British Journal of Psychology, 105, 35-56.

Jost, J. T. (2006). The End of the End of Ideology. American Psychologist, 61(7), 651-670.

Keeley, B. L. (1999). Of Conspiracy Theories. The Journal of Philosophy, 96(3), 109-126.

Kim, Y. (2019). How conspiracy theories can stimulate political engagement. Journal of Elections, Public Opinion and Parties, 0(0), 1-21.

King, M., \& Taylor, D. M. (2011). The Radicalization of Homegrown Jihadists: A Review of Theoretical Models and Social Psychological Evidence. Terrorism and Political Violence, 23(4), 602-622. 
Kriesi, H., Grande, E., Dolezal, M., Helbling, M., Höglinger, D., Hutter, S., \& Wüest, B. (2012). Political Conflict in Western Europe. Cambridge: Cambridge University Press.

Kruglanski, A. W., Bélanger, J. J., Gelfand, M., Gunaratna, R., Hettiarachchi, M., Reinares, F., Orehek, E., Sasota, J., \& Sharvit, K. (2013). Terrorism-a (self) love story: Redirecting the significance quest can end violence. The American Psychologist, 68(7), 559-575.

Kruglanski, A. W., Gelfand, M. J., Bélanger, J. J., Sheveland, A., Hetiarachchi, M., \& Gunaratna, R. (2014). The Psychology of Radicalization and Deradicalization: How Significance Quest Impacts Violent Extremism. Political Psychology, 35(S1), 69-93.

Lewandowsky, S., Oberauer, K., \& Gignac, G. E. (2013). NASA Faked the Moon Landing--Therefore, (Climate) Science Is a Hoax: An Anatomy of the Motivated Rejection of Science. Psychological Science, (24)5, 622-633.

Mann, T. E., \& Ornstein, N. J. (2012). It's Even Worse Than It Looks: How the American Constitutional System Collided With the New Politics of Extremism. Basic Books.

Mansbridge, J., \& Martin, C. J. (Eds.). (2013). Negotiating Agreement in Politics. Report of the Task Force on Negotiating Agreement in Politics. Washington: American Political Science Association.

McCarty, N., Poole, K. T., \& Rosenthal, H. (2006). Polarized America: The Dance of Ideology and Unequal Riches. MIT Press.

McCauley, C., \& Moskalenko, S. (2008). Mechanisms of Political Radicalization: Pathways Toward Terrorism. Terrorism and Political Violence, 20(3), 415-433.

McCauley, C., \& Moskalenko, S. (2011). Friction: How Radicalization Happens to Them and Us. Oxford University Press.

Moghaddam, F. M. (2005). The Staircase to Terrorism. A Psychological Exploration. American Psychologist, 60(2), 161-169.

Oliver, J. E., \& Wood, T. J. (2014). Conspiracy Theories and the Paranoid Style(s) of Mass Opinion. American Journal of Political Science, 58(4), 952-966.

Rico, G., Guinjoan, M., \& Anduiza, E. (2017). The Emotional Underpinnings of Populism: How Anger and Fear Affect Populist Attitudes. Swiss Political Science Review, 23(4), 444-461.

Sageman, M. (2008). A Strategy for Fighting International Islamist Terrorists. The ANNALS of the American Academy of Political and Social Science, 618, 223-231. 
Sapountzis, A., \& Condor, S. (2013). Conspiracy Accounts as Intergroup Theories: Challenging Dominant Understandings of Social Power and Political Legitimacy. Political Psychology, 34(5), $731-752$.

Silva, B. C., Vegetti, F., \& Littvay, L. (2017). The Elite Is Up to Something: Exploring the Relation Between Populism and Belief in Conspiracy Theories. Swiss Political Science Review, 23(4), 423443.

Silva, B. C., Bosancianu, C. M., \& Littvay, L. (2019). Multilevel Structural Equation Modeling. SAGE Publications.

Somer, M., \& McCoy, J. (2018). Déjà vu? Polarization and Endangered Democracies in the 21st Century. American Behavioral Scientist, 62(1), 3-15.

Somer, M., \& McCoy, J. (2019). Transformations through Polarizations and Global Threats to Democracy. The ANNALS of the American Academy of Political and Social Science, 681(1), 8-22.

Sternisko, A., Cichocka, A., \& Van Bavel, J. J. (2020). The dark side of social movements: Social identity, non-conformity, and the lure of conspiracy theories. Current Opinion in Psychology, 35, 16.

Swami, V., Chamorro-Premuzic, T., \& Furnham, A. (2010). Unanswered Questions: A Preliminary Investigation of Personality and Individual Difference Predictors of 9/11 Conspiracist Beliefs. Applied Cognitive Psychology, 24, 749-761.

Swami, V., Coles, R., Stieger, S., Pietschnig, J., Furnham, A., Rehim, S., \& Voracek, M. (2011). Conspiracist ideation in Britain and Austria: Evidence of a monological belief system and associations between individual psychological differences and real-world and fictitious conspiracy theories. British Journal of Psychology, 102, 443-463.

Thomsen, D. M. (2017). Opting Out of Congress. Cambridge University Press.

Tworzecki, H. (2019). Poland: A Case of Top-Down Polarization. The ANNALS of the American Academy of Political and Social Science, 681(1), 97-119.

Uscinski, J. E., \& Parent, J. M. (2014). American Conspiracy Theories. Oxford University Press.

Van Prooijen, J.-W., Krouwel, A. P. M., \& Pollet, T. V. (2015). Political Extremism Predicts Belief in Conspiracy Theories. Social Psychological and Personality Science, 6(5), 570-578.

Van Prooijen, J.-W., \& Jostmann, N. B. (2013). Belief in conspiracy theories: The influence of uncertainty and perceived morality. European Journal of Social Psychology, 43, 109-115. 
Vegetti, F. (2019). The Political Nature of Ideological Polarization: The Case of Hungary. The ANNALS of the American Academy of Political and Social Science, 681(1), 78-96.

Wilner, A. S., \& Dubouloz, C.-J. (2010). Homegrown terrorism and transformative learning: an interdisciplinary approach to understanding radicalization. Global Change, Peace \& Security: Formerly Pacifica Review: Peace, Security \& Global Change, 22(1), 33-51.

Young, T. J. (1990). Cult Violence and the Identity Movement. Cultic Studies Journal, 7(2), 150-159.

Zonis, M., \& Joseph, C. M. (1994). Conspiracy Thinking in the Middle East. Political Psychology, 15(3), 443-459. 


\section{Appendix 1 - Question wordings of the main batteries}

Attitudes Toward the Use of Violence to Achieve Political Goals - JPV (Jacskon et al. 2013):

Response categories: 1 (Always wrong) to 5 (Always right).

1. Use violence to protest against things they think are unfair

2. Writing and distributing leaflets that encourage violence.

3. Using violence to protest against effects of globalization.

4. Using violence in the name of religion to protest.

\section{Aggression (Buss \& Perry 1992):}

Response categories: 1 (Extremely uncharacteristic of me) to 7 (Extremely characteristic of me).

1. Once in a while I can't control the urge to strike another person.

2. Given enough provocation, I may hit another person

3. If somebody hits me, I hit back.

4. I get into fights a little more than the average person.

5. If I have to resort to violence to protect my rights, I will.

6. There are people who pushed me so far that we came to blows.

7. I can think of no good reason for ever hitting a person.

8. I have threatened people I know.

9. I have become so mad that I have broken things.

10. I tell my friends openly when I disagree with them.

11. I often find myself disagreeing with people.

12. When people annoy me, I may tell them what I think of them.

13. I can't help getting into arguments when people disagree with me.

14. My friends say that I'm somewhat argumentative.

15. I flare up quickly but get over it quickly.

16. When frustrated, I let my irritation show.

17. I sometimes feel like a powder keg ready to explode. 
18. I am an even-tempered person.

19. Some of my friends think I'm a hothead.

20. Sometimes I fly off the handle for no good reason.

21. I have trouble controlling my temper.

22. I am sometimes eaten up with jealousy.

23. At times I feel I have gotten a raw deal out of life.

24. Other people always seem to get the breaks.

25. I wonder why sometimes I feel so bitter about things.

26. I know that "friends" talk about me behind my back.

27. I am suspicious of overly friendly strangers.

28. I sometimes feel that people are laughing at me behind me back.

29. When people are especially nice, I wonder what they want

\section{Belief in Conspiracies (Brotherton et al. 2013):}

Response categories: 1 (Definitely not true) to 5 (Definitely true).

1. The government is involved in the murder of innocent citizens and/or well-known public figures, and keeps this a secret.

2. The power held by heads of state is second to that of small unknown groups who really control world politics.

3. Secret organisations communicate with extraterrestrials, but keep this fact from the public.

4. The spread of certain viruses and/or diseases is the result of the deliberate, concealed efforts of some organisation.

5. Groups of scientists manipulate, fabricate, or suppress evidence in order to deceive the public.

6. The government permits or perpetrates acts of terrorism on its own soil, disguising its involvement.

7. A small, secret group of people is responsible for making all major world decisions, such as going to war.

8. Evidence of alien contact is being concealed from the public.

9. Technology with mind-control capacities is used on people without their knowledge.

10. New and advanced technology which would harm current industry is being suppressed. 
11. The government uses people as patsies to hide its involvement in criminal activity.

12. Certain significant events have been the result of the activity of a small group who secretly manipulate world events.

13. Some UFO sightings and rumors are planned or staged in order to distract the public from real alien contact

14. Experiments involving new drugs or technologies are routinely carried out on the public without their knowledge or consent.

15. A lot of important information is deliberately concealed from the public out of self-interest. 


\section{Appendix 2 - Full models results}

Table 1: SEM model of justification of political violence (JPV) and conspiracy belief - regression coefficients. All coefficients are standardized. $N=646$

\begin{tabular}{ccccc}
\hline DV & IV & Coef & SE & p-value \\
\hline Conspiracy belief & Aggression & 0.286 & 0.043 & 0.000 \\
Conspiracy belief & RWA & 0.242 & 0.053 & 0.000 \\
Conspiracy belief & SDO & -0.048 & 0.054 & 0.379 \\
Conspiracy belief & Internal Efficacy & 0.092 & 0.042 & 0.028 \\
Conspiracy belief & Lib-Cons Ideology & 0.002 & 0.050 & 0.973 \\
Conspiracy belief & Age & -0.003 & 0.040 & 0.936 \\
Conspiracy belief & Income & -0.067 & 0.041 & 0.100 \\
Conspiracy belief & Education & -0.119 & 0.041 & 0.003 \\
Conspiracy belief & Gender (female) & 0.055 & 0.039 & 0.158 \\
Conspiracy belief & Non-white & 0.091 & 0.039 & 0.021 \\
\hline JPV & Conspiracy belief & 0.152 & 0.042 & 0.000 \\
JPV & Aggression & 0.239 & 0.045 & 0.000 \\
JPV & RWA & -0.016 & 0.053 & 0.758 \\
JPV & SDO & 0.226 & 0.051 & 0.000 \\
JPV & Internal Efficacy & -0.108 & 0.041 & 0.008 \\
JPV & Lib-Cons Ideology & -0.122 & 0.047 & 0.009 \\
JPV & Age & -0.051 & 0.039 & 0.182 \\
JPV & Income & -0.074 & 0.039 & 0.062 \\
JPV & Education & 0.088 & 0.040 & 0.027 \\
JPV & Gender (female) & -0.169 & 0.038 & 0.000 \\
JPV & Non-white & 0.017 & 0.038 & 0.658 \\
\hline Mediated effect of Aggression on JPV & 0.044 & 0.002 \\
Total effect of Aggression on JPV & 0.283 & 0.000 \\
\hline
\end{tabular}


Table 2: SEM model of legitimization of radical political action (LRPA) and conspiracy belief regression coefficients. All coefficients are standardized. $N=646$

\begin{tabular}{ccccc}
\hline DV & IV & Coef & SE & p-value \\
\hline Conspiracy belief & Aggression & 0.286 & 0.043 & 0.000 \\
Conspiracy belief & RWA & 0.242 & 0.053 & 0.000 \\
Conspiracy belief & SDO & -0.047 & 0.055 & 0.390 \\
Conspiracy belief & Internal Efficacy & 0.092 & 0.042 & 0.029 \\
Conspiracy belief & Lib-Cons Ideology & 0.001 & 0.050 & 0.976 \\
Conspiracy belief & Age & -0.003 & 0.040 & 0.939 \\
Conspiracy belief & Income & -0.067 & 0.041 & 0.096 \\
Conspiracy belief & Education & -0.118 & 0.041 & 0.004 \\
Conspiracy belief & Gender (female) & 0.054 & 0.039 & 0.160 \\
Conspiracy belief & Non-white & 0.091 & 0.039 & 0.021 \\
\hline LRPA & Conspiracy belief & 0.170 & 0.045 & 0.000 \\
LRPA & Aggression & 0.223 & 0.048 & 0.000 \\
LRPA & RWA & 0.015 & 0.058 & 0.796 \\
LRPA & SDO & 0.234 & 0.056 & 0.000 \\
LRPA & Internal Efficacy & -0.089 & 0.044 & 0.044 \\
LRPA & Lib-Cons Ideology & -0.103 & 0.051 & 0.044 \\
LRPA & Age & -0.100 & 0.041 & 0.016 \\
LRPA & Income & -0.006 & 0.042 & 0.880 \\
LRPA & Education & 0.101 & 0.042 & 0.017 \\
LRPA & Gender (female) & -0.114 & 0.041 & 0.005 \\
LRPA & Non-white & 0.026 & 0.041 & 0.530 \\
\hline Mediated effect of Aggression on LRPA & 0.049 & 0.021 & 0.002 \\
Total effect of Aggression on LRPA & 0.271 & 0.072 & 0.000 \\
\hline & & & &
\end{tabular}


Table 3: SEM model of justification of political violence (JPV) and conspiracy belief - measurement part. All coefficients are standardized. $N=646$

\begin{tabular}{ccccc}
\hline Latent & Manifest & Coef & SE & pvalue \\
\hline JPV & endvio1 & 0.815 & 0.017 & 0.000 \\
JPV & endvio2 & 0.596 & 0.028 & 0.000 \\
JPV & endvio3 & 0.942 & 0.012 & 0.000 \\
JPV & endvio4 & 0.701 & 0.022 & 0.000 \\
\hline Conspiracy belief & cons1 & 0.678 & 0.023 & 0.000 \\
Conspiracy belief & cons2 & 0.719 & 0.020 & 0.000 \\
Conspiracy belief & cons3 & 0.684 & 0.023 & 0.000 \\
Conspiracy belief & cons4 & 0.762 & 0.018 & 0.000 \\
Conspiracy belief & cons5 & 0.641 & 0.024 & 0.000 \\
Conspiracy belief & cons6 & 0.766 & 0.018 & 0.000 \\
Conspiracy belief & cons7 & 0.776 & 0.017 & 0.000 \\
Conspiracy belief & cons8 & 0.665 & 0.024 & 0.000 \\
Conspiracy belief & cons9 & 0.748 & 0.019 & 0.000 \\
Conspiracy belief & cons10 & 0.542 & 0.029 & 0.000 \\
Conspiracy belief & cons11 & 0.738 & 0.020 & 0.000 \\
Conspiracy belief & cons12 & 0.801 & 0.016 & 0.000 \\
Conspiracy belief & cons13 & 0.669 & 0.023 & 0.000 \\
Conspiracy belief & cons14 & 0.739 & 0.019 & 0.000 \\
Conspiracy belief & cons15 & 0.473 & 0.032 & 0.000 \\
\hline Aggression & agg1 & 0.585 & 0.041 & 0.000 \\
Aggression & agg2 & 0.557 & 0.042 & 0.000 \\
Aggression & agg3 & 0.453 & 0.052 & 0.000 \\
Aggression & agg4 & 0.668 & 0.035 & 0.000 \\
Aggression & agg5 & 0.389 & 0.051 & 0.000 \\
Aggression & agg6 & 0.535 & 0.043 & 0.000 \\
Aggression & agg7 & -0.194 & 0.061 & 0.001 \\
Aggression & agg8 & 0.661 & 0.036 & 0.000 \\
Aggression & agg9 & 0.713 & 0.030 & 0.000 \\
Aggression & agg10 & 0.139 & 0.062 & 0.026 \\
Aggression & agg11 & 0.542 & 0.043 & 0.000 \\
Aggression & agg12 & 0.411 & 0.053 & 0.000 \\
Aggression & agg13 & 0.649 & 0.035 & 0.000 \\
Aggression & agg14 & 0.592 & 0.042 & 0.000 \\
Aggression & agg15 & 0.526 & 0.046 & 0.000 \\
Aggression & agg16 & 0.521 & 0.045 & 0.000 \\
agg17 & 0.734 & 0.029 & 0.000 \\
agg18 & -0.491 & 0.046 & 0.000 \\
Aggron & 0.797 & 0.024 & 0.000 \\
Aggrion & 0.712 & 0.032 & 0.000 \\
\hline
\end{tabular}




\begin{tabular}{|c|c|c|c|c|}
\hline Aggression & $\operatorname{agg} 21$ & 0.771 & 0.026 & 0.000 \\
\hline Aggression & $\operatorname{agg} 22$ & 0.506 & 0.044 & 0.000 \\
\hline Aggression & $\operatorname{agg} 23$ & 0.493 & 0.044 & 0.000 \\
\hline Aggression & $\operatorname{agg} 24$ & 0.511 & 0.044 & 0.000 \\
\hline Aggression & $\operatorname{agg} 25$ & 0.567 & 0.040 & 0.000 \\
\hline Aggression & $\operatorname{agg} 26$ & 0.539 & 0.044 & 0.000 \\
\hline Aggression & $\operatorname{agg} 27$ & 0.321 & 0.057 & 0.000 \\
\hline Aggression & $\operatorname{agg} 28$ & 0.572 & 0.041 & 0.000 \\
\hline Aggression & $\operatorname{agg} 29$ & 0.521 & 0.044 & 0.000 \\
\hline RWA & rwa1 & 0.529 & 0.039 & 0.000 \\
\hline RWA & rwa2 & 0.554 & 0.038 & 0.000 \\
\hline RWA & rwa3 & 0.796 & 0.020 & 0.000 \\
\hline RWA & rwa4 & -0.687 & 0.028 & 0.000 \\
\hline RWA & rwa5 & 0.621 & 0.032 & 0.000 \\
\hline RWA & rwa6 & -0.684 & 0.029 & 0.000 \\
\hline RWA & rwa7 & 0.836 & 0.017 & 0.000 \\
\hline RWA & rwa8 & -0.566 & 0.036 & 0.000 \\
\hline RWA & rwa9 & -0.599 & 0.034 & 0.000 \\
\hline RWA & rwa10 & 0.829 & 0.018 & 0.000 \\
\hline RWA & rwa11 & -0.563 & 0.037 & 0.000 \\
\hline RWA & rwa12 & 0.800 & 0.020 & 0.000 \\
\hline RWA & rwa13 & -0.590 & 0.035 & 0.000 \\
\hline RWA & rwa14 & 0.769 & 0.022 & 0.000 \\
\hline RWA & rwa15 & -0.560 & 0.036 & 0.000 \\
\hline RWA & rwa16 & 0.796 & 0.021 & 0.000 \\
\hline RWA & rwa17 & 0.720 & 0.027 & 0.000 \\
\hline RWA & rwa18 & -0.521 & 0.039 & 0.000 \\
\hline RWA & rwa19 & 0.659 & 0.031 & 0.000 \\
\hline SDO & sdo1 & 0.711 & 0.028 & 0.000 \\
\hline SDO & sdo2 & 0.537 & 0.039 & 0.000 \\
\hline $\mathrm{SDO}$ & sdo3 & 0.685 & 0.029 & 0.000 \\
\hline SDO & sdo4 & 0.604 & 0.036 & 0.000 \\
\hline $\mathrm{SDO}$ & sdo5 & 0.582 & 0.036 & 0.000 \\
\hline $\mathrm{SDO}$ & sdo6 & 0.718 & 0.027 & 0.000 \\
\hline SDO & sdo7 & 0.626 & 0.034 & 0.000 \\
\hline $\mathrm{SDO}$ & sdo8 & 0.701 & 0.030 & 0.000 \\
\hline SDO & sdo9 & -0.777 & 0.024 & 0.000 \\
\hline SDO & sdo10 & -0.740 & 0.028 & 0.000 \\
\hline SDO & sdo11 & -0.697 & 0.028 & 0.000 \\
\hline SDO & sdo12 & -0.794 & 0.023 & 0.000 \\
\hline SDO & sdo13 & -0.761 & 0.025 & 0.000 \\
\hline SDO & sdo14 & -0.741 & 0.026 & 0.000 \\
\hline SDO & sdo15 & -0.570 & 0.039 & 0.000 \\
\hline
\end{tabular}




\begin{tabular}{ccccc} 
SDO & sdo16 & -0.662 & 0.030 & 0.000 \\
\hline Internal Efficacy & intself1 & 0.784 & 0.023 & 0.000 \\
Internal Efficacy & intself2 & 0.827 & 0.019 & 0.000 \\
Internal Efficacy & intself3 & 0.757 & 0.024 & 0.000 \\
Internal Efficacy & intself4 & 0.824 & 0.020 & 0.000 \\
Internal Efficacy & intself5 & 0.859 & 0.016 & 0.000 \\
Internal Efficacy & intself6 & 0.826 & 0.019 & 0.000 \\
Internal Efficacy & intself7 & 0.660 & 0.031 & 0.000 \\
Internal Efficacy & intself8 & 0.823 & 0.019 & 0.000 \\
\hline
\end{tabular}


Table 4: SEM model of legitimization of radical political action (LRPA) and conspiracy belief measurement part. All coefficients are standardized. $N=646$

\begin{tabular}{ccccc}
\hline Latent & Manifest & Coef & SE & p-value \\
\hline LRPA & radact1 & 0.738 & 0.028 & 0.000 \\
LRPA & radact2 & 0.801 & 0.024 & 0.000 \\
LRPA & radact3 & 0.851 & 0.023 & 0.000 \\
LRPA & radact5 & 0.838 & 0.022 & 0.000 \\
LRPA & radact6 & 0.629 & 0.035 & 0.000 \\
\hline Conspiracy belief & cons1 & 0.678 & 0.023 & 0.000 \\
Conspiracy belief & cons2 & 0.719 & 0.020 & 0.000 \\
Conspiracy belief & cons3 & 0.685 & 0.023 & 0.000 \\
Conspiracy belief & cons4 & 0.762 & 0.018 & 0.000 \\
Conspiracy belief & cons5 & 0.640 & 0.024 & 0.000 \\
Conspiracy belief & cons6 & 0.766 & 0.018 & 0.000 \\
Conspiracy belief & cons7 & 0.776 & 0.017 & 0.000 \\
Conspiracy belief & cons8 & 0.666 & 0.024 & 0.000 \\
Conspiracy belief & cons9 & 0.748 & 0.019 & 0.000 \\
Conspiracy belief & cons10 & 0.542 & 0.029 & 0.000 \\
Conspiracy belief & cons11 & 0.739 & 0.020 & 0.000 \\
Conspiracy belief & cons12 & 0.801 & 0.016 & 0.000 \\
Conspiracy belief & cons13 & 0.669 & 0.023 & 0.000 \\
Conspiracy belief & cons14 & 0.739 & 0.019 & 0.000 \\
Conspiracy belief & cons15 & 0.473 & 0.032 & 0.000 \\
\hline Aggression & agg1 & 0.585 & 0.041 & 0.000 \\
Aggression & agg2 & 0.560 & 0.041 & 0.000 \\
Aggression & agg3 & 0.454 & 0.052 & 0.000 \\
Aggression & agg4 & 0.667 & 0.035 & 0.000 \\
Aggression & agg5 & 0.388 & 0.051 & 0.000 \\
Aggression & agg6 & 0.535 & 0.043 & 0.000 \\
Aggression & agg7 & -0.196 & 0.061 & 0.001 \\
Aggression & agg8 & 0.661 & 0.036 & 0.000 \\
Aggression & agg9 & 0.713 & 0.030 & 0.000 \\
Aggression & agg10 & 0.143 & 0.062 & 0.021 \\
Aggression & agg11 & 0.545 & 0.043 & 0.000 \\
Aggression & agg12 & 0.410 & 0.053 & 0.000 \\
Aggression & agg13 & 0.650 & 0.035 & 0.000 \\
aggression & agg14 & 0.594 & 0.042 & 0.000 \\
agg15 & 0.526 & 0.046 & 0.000 \\
agg16 & 0.520 & 0.045 & 0.000 \\
agg17 & 0.734 & 0.029 & 0.000 \\
Agg19 & 0.797 & 0.047 & 0.000 \\
Aggren & & & & 0.000
\end{tabular}




\begin{tabular}{|c|c|c|c|c|}
\hline Aggression & $\operatorname{agg} 20$ & 0.710 & 0.032 & 0.000 \\
\hline Aggression & $\operatorname{agg} 21$ & 0.772 & 0.026 & 0.000 \\
\hline Aggression & $\operatorname{agg} 22$ & 0.504 & 0.044 & 0.000 \\
\hline Aggression & $\operatorname{agg} 23$ & 0.493 & 0.044 & 0.000 \\
\hline Aggression & $\operatorname{agg} 24$ & 0.510 & 0.045 & 0.000 \\
\hline Aggression & $\operatorname{agg} 25$ & 0.568 & 0.040 & 0.000 \\
\hline Aggression & $\operatorname{agg} 26$ & 0.540 & 0.044 & 0.000 \\
\hline Aggression & $\operatorname{agg} 27$ & 0.322 & 0.057 & 0.000 \\
\hline Aggression & $\operatorname{agg} 28$ & 0.571 & 0.041 & 0.000 \\
\hline Aggression & $\operatorname{agg} 29$ & 0.522 & 0.044 & 0.000 \\
\hline RWA & rwa1 & 0.529 & 0.039 & 0.000 \\
\hline RWA & rwa2 & 0.554 & 0.038 & 0.000 \\
\hline RWA & rwa3 & 0.796 & 0.020 & 0.000 \\
\hline RWA & rwa4 & -0.687 & 0.028 & 0.000 \\
\hline RWA & rwa5 & 0.621 & 0.032 & 0.000 \\
\hline RWA & rwa6 & -0.684 & 0.029 & 0.000 \\
\hline RWA & rwa7 & 0.836 & 0.017 & 0.000 \\
\hline RWA & rwa8 & -0.566 & 0.036 & 0.000 \\
\hline RWA & rwa9 & -0.599 & 0.034 & 0.000 \\
\hline RWA & rwa10 & 0.829 & 0.018 & 0.000 \\
\hline RWA & rwa11 & -0.563 & 0.037 & 0.000 \\
\hline RWA & rwa12 & 0.800 & 0.020 & 0.000 \\
\hline RWA & rwa13 & -0.590 & 0.035 & 0.000 \\
\hline RWA & rwa14 & 0.769 & 0.022 & 0.000 \\
\hline RWA & rwa15 & -0.560 & 0.036 & 0.000 \\
\hline RWA & rwa16 & 0.796 & 0.021 & 0.000 \\
\hline RWA & rwa17 & 0.720 & 0.027 & 0.000 \\
\hline RWA & rwa18 & -0.521 & 0.039 & 0.000 \\
\hline RWA & rwa19 & 0.659 & 0.031 & 0.000 \\
\hline $\mathrm{SDO}$ & sdo1 & 0.715 & 0.028 & 0.000 \\
\hline SDO & sdo2 & 0.539 & 0.039 & 0.000 \\
\hline $\mathrm{SDO}$ & sdo3 & 0.684 & 0.029 & 0.000 \\
\hline SDO & sdo4 & 0.604 & 0.036 & 0.000 \\
\hline SDO & sdo5 & 0.585 & 0.036 & 0.000 \\
\hline SDO & sdo6 & 0.722 & 0.027 & 0.000 \\
\hline $\mathrm{SDO}$ & sdo7 & 0.624 & 0.034 & 0.000 \\
\hline SDO & sdo8 & 0.702 & 0.030 & 0.000 \\
\hline SDO & sdo9 & -0.774 & 0.024 & 0.000 \\
\hline SDO & sdo10 & -0.737 & 0.028 & 0.000 \\
\hline $\mathrm{SDO}$ & sdo11 & -0.697 & 0.028 & 0.000 \\
\hline SDO & sdo12 & -0.792 & 0.023 & 0.000 \\
\hline SDO & sdo13 & -0.761 & 0.025 & 0.000 \\
\hline SDO & sdo14 & -0.741 & 0.026 & 0.000 \\
\hline
\end{tabular}




\begin{tabular}{ccccc} 
SDO & sdo15 & -0.568 & 0.039 & 0.000 \\
SDO & sdo16 & -0.659 & 0.031 & 0.000 \\
\hline Internal Efficacy & intself1 & 0.784 & 0.023 & 0.000 \\
Internal Efficacy & intself2 & 0.827 & 0.019 & 0.000 \\
Internal Efficacy & intself3 & 0.756 & 0.025 & 0.000 \\
Internal Efficacy & intself4 & 0.823 & 0.020 & 0.000 \\
Internal Efficacy & intself5 & 0.860 & 0.016 & 0.000 \\
Internal Efficacy & intself6 & 0.826 & 0.019 & 0.000 \\
Internal Efficacy & intself7 & 0.661 & 0.031 & 0.000 \\
Internal Efficacy & intself8 & 0.824 & 0.019 & 0.000 \\
\hline
\end{tabular}

